\section{OPEN ACCESS}

Edited by:

Carmen Gianfrani,

Institute of Biochemistry and Cell

Biology (CNR), Italy

Reviewed by:

Alberto Finamore,

Council for Agricultural and

Economics Research, Italy

Hu Wang,

Johns Hopkins University,

United States

*Correspondence:

Giorgia Renga

rengagiorgia@gmail.com

Specialty section

This article was submitted to Nutritional Immunology,

a section of the journal

Frontiers in Immunology

Received: 30 August 2019 Accepted: 19 November 2019 Published: 05 December 2019

Citation:

Renga G, Bellet MM, Stincardini C, Pariano M, Oikonomou V, Villella VR, Brancorsini S, Clerici C, Romani $L$ and Costantini C (2019) To Be or Not to Be a Pathogen: Candida albicans and Celiac Disease.

Front. Immunol. 10:2844. doi: 10.3389/fimmu.2019.02844

\title{
To Be or Not to Be a Pathogen: Candida albicans and Celiac Disease
}

\section{Giorgia Renga ${ }^{1 *}$, Marina M. Bellet ${ }^{1}$, Claudia Stincardini ${ }^{1}$, Marilena Pariano ${ }^{1}$, Vasilis Oikonomou ${ }^{1}$, Valeria R. Villella ${ }^{2}$, Stefano Brancorsini ${ }^{1}$, Carlo Clerici ${ }^{3}$, Luigina Romani ${ }^{1}$ and Claudio Costantini ${ }^{1}$}

${ }^{1}$ Department of Experimental Medicine, University of Perugia, Perugia, Italy, ${ }^{2}$ Division of Genetics and Cell Biology, European Institute for Research in Cystic Fibrosis, San Raffaele Scientific Institute, Milan, Italy, ${ }^{3}$ Gastroenterology Unit, Santa Maria della Misericordia Hospital of Perugia, Perugia, Italy

Celiac disease (CD) is an immune-mediated disorder triggered by the ingestion of gluten and characterized by reversible small-bowel mucosal atrophy in genetically predisposed subjects. Although the prevalence of CD has increased, many aspects of this pathology are still unrecognized. Candida albicans, a commensal of the human gastrointestinal tract, has been linked to CD for a long time based, among others, upon the observation of similarity between the fungal wall component, hyphal wall protein 1, and CD-related gliadin T-cell epitopes. We have recently demonstrated that Candida may switch from commensal to pathogen contingent upon several players, including mast cells, key sentinels of the immune system at the interface between the environment and the host, and the pleiotropic cytokine IL-9. However, other factors are likely to play a role by altering the balance between inflammation and tolerance. In this regard, tryptophan and its metabolites are increasingly being recognized in promoting mucosal homeostasis by balancing the immune response to external cues. Based on these premises, we will discuss how the output of Candida colonization in the gut is highly contextual, being determined at the intersection of many immunological (IL-9/mast cells) and metabolic (tryptophan) pathways that ultimately dictate the Candida commensalism vs. pathogenicity in $C D$, thus paving the way for novel therapeutic opportunities in $C D$.

\section{Keywords: celiac disease, Candida albicans, mast cells, IL-9, tryptophan, immune tolerance}

\section{INTRODUCTION}

Celiac disease (CD) is an immune-mediated disorder triggered by the ingestion of gluten, a major protein in wheat, and characterized by reversible small-bowel mucosal atrophy in genetically predisposed subjects. CD affects about $1 \%$ of people in most populations but evidence suggests that the prevalence is increasing. Although the prevalence of celiac disease has increased, this pathology is still unrecognized. CD symptoms can appear from childhood to senior adulthood although the average age of diagnosis is between the 4th and 6th decades of life, indicating an important role of age in the onset of the disease. An early diagnosis is important to reduce the intestinal and extra-intestinal damages due to the recurrent gluten exposure. Unfortunately, it has been reported that for each clinical diagnosis of $\mathrm{CD}$, an average of 5 to 10 individuals remains undiagnosed. The failure to diagnosis CD is usually due to atypical, minimal or even absent symptoms (1). The patients presenting malabsorption, weight loss, and steatorrhea are a small proportion of the total population affected by $\mathrm{CD}$. For this reason, over 10 years ago, Ferguson et al. compared $\mathrm{CD}$ to 
an iceberg in which symptomatic patients represent the visible peak and asymptomatic subjects the invisible part of the floating rock (2). Interestingly, several studies have indicated that CD is diagnosed predominantly in women and this is partially due to increased prevalence in women relative to men, to the fact that women use healthcare services more than men and that women have the highest risk to develop autoimmune conditions (3-5). As a matter of fact, the symptoms of $\mathrm{CD}$ in women are more severe and rapid than in men (6).

The major environmental factor for the development of $\mathrm{CD}$ is gliadin, a monomeric protein contained in the gluten, rich in glutamine and proline. This chemical structure renders part of the molecule resistant to proteolytic degradation by gastrointestinal enzymes, leaving large peptides up to 33 amino acids long (7). In healthy people, most of these peptides are simply excreted without triggering the immune response. On the contrary, in $\mathrm{CD}$ subjects the deamidation of peptides by the enzyme tissue transglutaminase 2 (tTG2) increases the immunogenicity of gliadin, favoring the binding to the HLA-DQ2 or HLA-DQ8 molecules situated on antigen presenting cells. This leads to the exaggerated activation of the adaptive immune response mediated by $\mathrm{CD}^{+} \mathrm{T}$ cells $(8,9)$. Interestingly, only a small portion of individuals with at-risk HLA exposed to gluten develop CD, suggesting that both factors are necessary but not sufficient for developing CD (10). Thus, others environmental factors are possibly involved in the switches of the tolerance-immune activation balance in CD. Among these, the spectrum of intestinal microorganisms and how they change over time are considered to be important (11). In this regard, the similarity between the hyphal wall protein 1 (Hwp1) of Candida albicans, the major fungal commensal residing in the human gastrointestinal tract and two CD-related gliadin T-cell epitopes $(12,13)$, the humoral cross-reactivity between Hwp1 and gliadin (14) and the high fecal counts of Candida yeasts observed in CD patients (15) have all been taken to implicate Candida in the pathogenesis of CD.

Herein, we will discuss how the output of Candida colonization in the gut is highly contextual, being determined at the intersection of many immunological (IL-9/mast cells) and metabolic (tryptophan) pathways that ultimately dictate the Candida commensalism vs. pathogenicity in CD.

\section{MAST CELLS: WHEN SENTINELS BECOME INFLAMMATORY CULPRITS IN CD}

Although CD is considered a $\mathrm{T}$ cell-mediated enteropathy, there is growing evidence supporting the crucial role of innate immunity in the development of CD (16). It is therefore critical to study the role of innate immunity in the inductive and effector phases of disease in order to understand the disease as a whole. Mast cells (MCs) are tissue-resident cells typically located at the strategical location involved in host defense and belong to the innate immune system. MCs are abundant in the gastrointestinal tract and consist $\sim 2-3 \%$ within the lamina propria in healthy individuals (17). The everchanging environment characteristics of the intestinal tract contribute to MC switching phenotypes, a transdifferentiation process by which MCs synthesize and release specific mediators depending on the environment, so influencing their unique ability to regulate homeostasis or promote inflammatory processes (18). Thus, MCs are viewed as important sentinels in host defense against bacterial, viral and parasitic infections but also as promoters of several gastrointestinal diseases such as food allergy $(19,20)$. Based on the protease expression, MCs can be distinguished in mice into mucosal-type MCs (MMCs), located in mucosal compartments and expressing the proteases chymase, and to connective tissue-type MCs (CTMCs), located in submucosa and expressing the proteases chymase, tryptase and carboxypeptidase A (21). Several studies have highlighted that aberrant MC activation is associated with increased intestinal permeability and inflammation (22). MCderived tryptase induces acute intestinal inflammatory responses by activating a protease-activated receptor 2 expressed on the intestinal epithelial cells (23). This activation leads to a redistribution of zonulin and occludin, two important proteins that ensure the integrity of intestinal barrier, resulting in increased permeability (24).

Because of the ability to disrupt intestinal epithelial barrier, MCs are known to promote inflammation upon repeated exposure of ingested antigen. In 2015, Chen et al. demonstrated that MMCs considerably expand after repeated exposure to ingested antigens, thus favoring food allergic response and systemic anaphylaxis (25). Of interest, these cells can secrete prodigious amount of IL-9, a pleiotropic cytokine produced by both innate and adaptive immunity cells (26), suggesting that IL-9 and MCs may synergize to develop food allergy. In fact, mice ablated of MMC-IL-9-dependent cells failed to develop intestinal mastocytosis, which resulted in decreased food allergy symptoms promptly restored by the adoptive transfer of these cells (25). The dual capability of MCs to both promote epithelial damage and aggravate food allergy symptoms may result destructive in CD. Several reports documented an increased $\mathrm{MC}$ number in the untreated $\mathrm{CD}$ subjects that returns to normal levels after gluten withdrawal. Conversely, others showed a lower MC number in intestinal biopsies from untreated $\mathrm{CD}$ patients compared to healthy subjects, which return to the normal range in patients subjected to a gluten-free diet (27). More recently, 20 subjects with nonceliac gluten sensitivity and $16 \mathrm{CD}$ patients were enrolled to evaluate the expression of specific markers of the innate immune system and have shown an increased MC accumulation in the intestinal mucosa on both groups (28). In addition, Frossi et al. have found that the increased density of infiltrating MCs in CD intestinal biopsies correlates with an increased inflammatory grade, according to the Marsh classification, and that, by activating the MyD88 pathways, MCs release in vitro inflammatory cytokines and skew myeloid populations toward a Th1-polarizing environment (29).

All in all, these results indicate that MC plasticity may be a double-edged sword in $\mathrm{CD}$ and as-yet uncharacterized environmental changes can drive MCs to exacerbate mucosal 
inflammation by impairing barrier integrity and promoting food allergy.

\section{CANDIDA ALBICANS: TO BE OR NOT TO BE A PATHOGEN IN CD}

C. albicans is a human commensal with an extraordinary ability to well-adapt for growth in the gastrointestinal tract because of a delicate interplay between host immunity, the microbiota, and the fungus (30-32). The ability to survive as a commensal in several anatomically distinct sites, each with its own specific set of environmental pressures, and switch to pathobiont in particular conditions is at the base of Candida virulence. The transition between yeast and hyphal morphologies is thought to underlie much of the variation in virulence observed in several host tissues (30).

As already mentioned, the hypothesis that C. albicans may be a trigger in $\mathrm{CD}$ has been proposed after the observation of similarity between Hwp1 and two CD-related gliadin T-cell epitopes. The high homology allows tissue TG2 to covalently link fungal protein and enable Candida to adhere strongly to the intestinal epithelium $(12,33)$. This hypothesis has been supported by the finding of higher levels of anti-Hwp1, anti-gliadin and anti-TG2 antibodies in the serum of $\mathrm{CD}$ patients more than healthy controls, suggesting that the presence of Candida in CD may activate an unstrained immune response that, at least in susceptible individuals, may lead to increased inflammation and the characteristic villous atrophy (14). In addition, Harnett et al. were able to detect Candida sp. in 33\% of CD fecal specimens compared to $0 \%$ of the control group confirming the idea that Candida may act as a trigger of autoimmune responses in genetically predisposed subjects (15). Thus, fungal components might potentially contribute to $\mathrm{CD}$ pathogenesis by modifying immunogenic epitopes of gluten and ensuing immune response. However, C. albicans is well-adapted for growth in the gastrointestinal tract where inflammation may perturb the resident bacterial community creating conditions that favor Candida colonization and inflammation. In fact, despite being implicated in intestinal immunopathology and sensitization to food antigens (34), C. albicans colonization also protects against local (31) and distant (35) immune pathologies in mice $(36,37)$.

Collectively, our current knowledge on the behavior of C. albicans in the gastrointestinal tract depicts a scenario in which the environmental conditions coupled to the individual genetic susceptibility impacts on the relationship between the host and $C$. albicans that may be either protective or pathogenic. Sorting out the key factors that tip the balance in either direction may be instrumental for future therapeutic approaches.

\section{IL-9 AND CANDIDA: A FATAL DUO IN CD}

Growth factors, cytokines, intestinal bacteria, dietary components, and proteases are known to regulate the intestinal barrier function. Particularly, cytokines can alter directly or indirectly the intestinal permeability by both influencing the structure and function of the tight junctions, multi-protein complexes that seal the space between adjacent cells $(38,39)$, and favoring the commensal-to-pathogen transition of gut microbes (40-42). This seems to be the case for IL-9 known to be able to regulate the intestinal barrier function. Indeed, it has been demonstrated that IL-9-deficient mice fail to develop experimental oral antigen-induced intestinal anaphylaxis. On the contrary, the IL-9 overexpression predisposed to oral antigen sensitization and increased the intestinal permeability (43). In addition, Gerlach et al. showed that IL-9 deficiency reduces inflammatory parameters in acute murine colitis by influencing the expression of occludin and claudin-1 (44). The ability to impair barrier function and predispose to food allergy points to IL-9 as a critical determinant in the predisposition to several gastrointestinal diseases such as $\mathrm{CD}$.

Beyond its ability to affect the intestinal epithelial barrier, IL-9 acts on Candida behavior. We recently demonstrated that IL-9 and MMCs induce an inflammatory status that promotes barrier function loss and fungal dissemination. This condition favoring Candida transition from commensal to pathobiont may be dangerous when a proper adaptive immune response does not occur as in the case of CD (45). As expected, we observed an increased IL-9 positivity in the duodenal biopsies from CD patients that correlated with enhanced inflammation as well as an increased susceptibility of gluten-sensitized mice upon infection with the fungus (45). These results suggest that the IL-9/MC axis could be an attractive drugable pathway to prevent the clinical unwanted consequences of fungal colonization. However, the occurrence of Candida pneumonia in patients receiving imatinib mesylate treatment suggests that MC-targeted therapy might predispose patients to opportunistic and life-threatening fungal infections (46). We have provided a plausible explanation for MC-mediated protection in the gut. Consistent with their immunoregulatory role on adaptive immune responses, tissue remodeling, homeostasis and peripheral tolerance $(47,48)$, CTMC promoted intestinal immune tolerance via the activation of different tryptophan (trp) metabolic pathways (45). We have found that IL-9 activates CTMC for local immune tolerance via both the indoleamine 2,3-dioxygenase (IDO) 1 and the trp hydroxylase 1 (TPH1) enzymatic pathways (45). Thus, the relative high levels of IL-9 and MMC observed in biopsies from patients with $\mathrm{CD}$ may promote an inflammation-driven intestinal dysbiosis to which trp deficiency may contribute. As microbiota perturbation was observed in condition of IL-9 or MC deficiency (45), we concluded that the IL9/MC axis, by integrating signals derived from the perturbed host/microbiota homeostasis, might act as signature that discriminates between the pathogenic vs. protective role of the fungus in the gut.

In conclusion, IL-9 may play a dual action in the gastrointestinal tract and, similarly to MCs and Candida, to which IL-9 is linked by an intricate cross-talk, opposite outcomes may come out, that could either result in protection, with the induction of a tolerogenic state, or 
disease, with inflammation and Candida transition to a pathogenic state.

\section{THE TRP METABOLIC PATHWAYS: NEW PLAYERS IN CD}

Oral tolerance is a specific type of peripheral tolerance that prevents hypersensitivity reactions induced by the exposure of antigen (49) and is defective in CD. Different mechanisms mediate development and expression of tolerance and among these, the trp metabolic pathways are highly relevant. Trp is an essential aromatic amino acid that human beings obtain through diet. Dietary trp can directly be converted by host IDO1 or TPH1 enzymes into kynurenines (50) or serotonin (5HT) (51), respectively, and by gut microbiota into ligands for aryl hydrocarbon receptor (AhR) (52). Thus, the host and the microbiota influence the trp catabolism and are critical inducers of regulatory responses in the gut $(53,54)$. A breakdown in regulatory mechanisms results in a set of chronic inflammatory conditions such as in CD (55). Several studies have reported a microbial dysbiosis in CD. Indeed, CD patients show a lower rate of beneficial to harmful bacteria compared to healthy controls and this is probably due to inherited differences in the expression of carbohydrates (56). The altered intestinal microbiota composition observed in CD led to increased IDO1 expression in myeloid cells of the intestinal lamina propria with increased levels of kynurenines $(57,58)$. Kynurenines play a tolerogenic role by promoting regulatory $\mathrm{T}$ cells (Tregs) (59). In $\mathrm{CD}$, there are conflicting studies on Tregs function. Some studies indicated that Tregs have impaired suppressive function and this might cause loss of tolerance to gluten, but also to self-antigens $(60,61)$, while others reported a higher density of
$\mathrm{CD} 4{ }^{+} \mathrm{CD} 25^{+}$Foxp $^{+} \mathrm{T}$ cells in duodenal biopsies of active CD patients compared to treated $\mathrm{CD}$ and control group. Despite the massive recruitment of Tregs in situ by gliadin, the authors described an ineffective control on $\mathrm{CD}^{+}$effector $\mathrm{T}$ cells by Tregs, likely due to the blocking function of IL-15, IL-21, and IFN- $\gamma$ in CD subjects (62-64).

The inability of Tregs to control inflammatory response may be also due to the defective AhR signaling observed in $\mathrm{CD}$. AhR is a ligand-dependent transcription factor that senses both xenobiotic and endogenous ligands, including microbiotaderived factors, and regulates immune homeostasis in the gut through IL-22 (65). The expansion of Tregs is a process that, at least partially, also requires the activation of AhR. In fact, kynurenines act as ligand for $\mathrm{AhR}$ and this leads $\mathrm{AhR}$ to translocate into the nucleus where it induces the expression of Foxp3 (59). Recently, Dinallo et al. documented a diminished AhR expression in the intestinal mucosa of patients with active $\mathrm{CD}$ as compared with inactive $\mathrm{CD}$ patients and normal controls suggesting that defective $\mathrm{AhR}$ signaling could contribute to amplify detrimental immune signals in CD mucosa (66). As most AhR ligands in the gut are of microbial origin (67), this directly links gut microbial dysbiosis to loss of immune tolerance in CD.

Beside the kynurenine pathway, trp degradation leads to the production of 5-HT. 5-HT is a neurotransmitter involved in the regulation of numerous biological functions. While 5 -HT is known to act primarily on the brain, close to $95 \%$ is synthesized and released by the enterochromaffin cells of the gut, in which 5HT maintains host defense. Many evidences link depression and gluten intolerance to serotonergic deficiency $(68,69)$. A study on rats showed that brain 5-HT levels decreased after the rats were fed wheat (70). Another study found that the majority of adolescents with $\mathrm{CD}$ display depressive symptoms before the

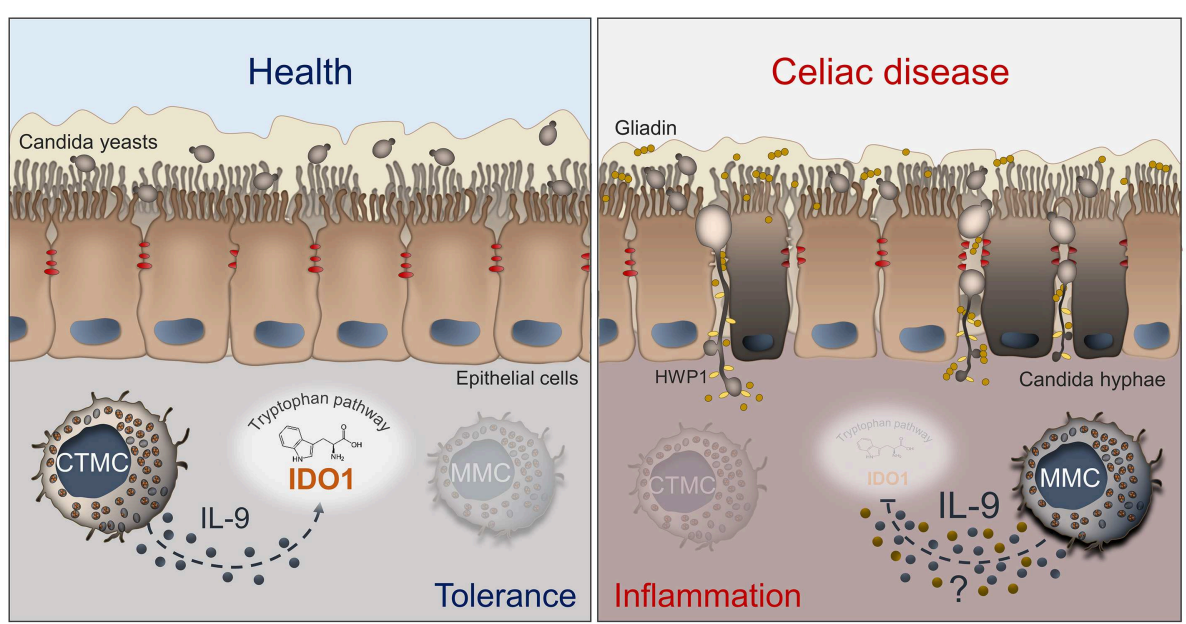

FIGURE 1 | Schematic depiction of the interactions between Candida, MCs and IL-9 in celiac disease. The left panel shows that, in healthy conditions, C. albicans is commensal in the gut and mucosal homeostasis is maintained by CTMCs that, by producing low levels of IL-9 (blue dots), sustain IDO1 activity and tolerance. In the right panel, what may happen in celiac disease is depicted. The barrier integrity is disrupted and Candida switches from the yeast to the hyphal form and crosses the epithelial lining, thus contributing to tissue damage. The pathogenic switch of Candida is favored by the predominance of MMCs that inhibit the activity of IDO1 by producing high levels of IL-9 and likely other inflammatory factors (yellow dots). Details are described in the text. CTMC, connective tissue-type mast cells; IDO1, indoleamine 2,3-dioxygenase; HWP1, hyphal wall protein; MMC, mucosal-type mast cells. 
diagnosis of $\mathrm{CD}$ and have low free trp levels. After conducting a gluten-free diet, $\mathrm{CD}$ subjects showed the improvement of depressive symptoms and increased levels of free trp levels (71). After 1 year on a gluten-free diet, patients experienced a significant increase in 5-HT (72). By contrast, other studies observed an increased level of 5-HT in CD. In 2006, Coleman et al. observed an increased number of ECs and significantly high peak level of 5-HT both in plasma and in duodenum of CD subjects (73). In addition, Di Sabatino et al. reported a significantly increase of ECs and 5-HT in the gut of refractory CD (74).

Trp metabolism plays a pivotal role also in the regulation of the immune response against $C$. albicans. On the one hand, the microbial-dependent AhR/IL-22 axis controls the initial fungal growth and infectivity at mucosal surfaces (52); on the other, host IDO1 and kynurenines prevent dysregulated immunity caused by Candida (75). In addition, the interaction between 5-HT and Candida may diminish the virulence properties of the fungus suggesting an important role also for 5-HT in antifungal host defense (76).

The activation of trp metabolic pathways and the generation of bioactive molecules with a role in maintaining mucosal homeostasis in the gastrointestinal tract-in terms of microbial eubiosis, immune tolerance, and control of Candida virulenceare emerging as key players in gut health. Their dysregulation may play a causative role in $\mathrm{CD}$ thus representing potential targets for therapeutic strategies.

\section{REFERENCES}

1. Lebwohl B, Sanders DS, Green PHR. Coeliac disease. Lancet. (2018) 391:7081. doi: 10.1016/S0140-6736(17)31796-8

2. Ferguson A, Arranz E, O'Mahony S. Clinical and pathological spectrum of coeliac disease-active, silent, latent, potential. Gut. (1993) 34:150-1. doi: 10.1136/gut.34.2.150

3. Fairweather D, Frisancho-Kiss S, Rose NR. Sex differences in autoimmune disease from a pathological perspective. Am J Pathol. (2008) 173:600-9. doi: 10.2353/ajpath.2008.071008

4. Pinkhasov RM, Wong J, Kashanian J, Lee M, Samadi DB, Pinkhasov MM, et al. Are men shortchanged on health? Perspective on health care utilization and health risk behavior in men and women in the United States. Int J Clin Pract. (2010) 64:475-87. doi: 10.1111/j.1742-1241.2009.02290.x

5. Shah S, Leffler D. Celiac disease: an underappreciated issue in women's health. Womens Health. (2010) 6:753-66. doi: 10.2217/WHE.10.57

6. Ciacci C, Cirillo M, Sollazzo R, Savino G, Sabbatini F, Mazzacca G. Gender and clinical presentation in adult celiac disease. Scand J Gastroenterol. (1995) 30:1077-81. doi: 10.3109/00365529509101610

7. Shan L, Molberg O, Parrot I, Hausch F, Filiz F, Gray GM, et al. Structural basis for gluten intolerance in celiac sprue. Science. (2002) 297:2275-9. doi: $10.1126 /$ science.1074129

8. Lundin KE, Scott H, Hansen T, Paulsen G, Halstensen TS, Fausa O, et al. Gliadin-specific, HLA-DQ(alpha $1^{*} 0501$,beta $1^{*} 0201$ ) restricted T cells isolated from the small intestinal mucosa of celiac disease patients. J Exp Med. (1993) 178:187-96. doi: 10.1084/jem.178.1.187

9. Molberg O, McAdam SN, Korner R, Quarsten H, Kristiansen C, Madsen L, et al. Tissue transglutaminase selectively modifies gliadin peptides that are recognized by gut-derived T cells in celiac disease. Nat Med. (1998) 4:713-7. doi: 10.1038/nm0698-713

10. Mazzilli MC, Ferrante P, Mariani P, Martone E, Petronzelli F, Triglione P, et al. A study of Italian pediatric celiac disease patients confirms that the primary

\section{CONCLUSION}

Despite increasing knowledge about CD, further avenues of investigation are necessary to better understand the pathogenesis and improve the treatment of patients with this condition. For a long time, C. albicans has been proposed as a possible trigger in CD. However, our recent study suggests a more intriguing role of $C$. albicans at the host/microbiota interface in CD (Figure 1). A better definition of this model might provide a unique opportunity for: (i) rationale antifungal therapy in $\mathrm{CD}$ by stratifying patients according to their immune and metabolic risk to develop a pathological Candida infection; (ii) use of IL-9 inhibitors to restore epithelial homeostasis in condition of inflammatory and dysbiotic damage; (iii) develop novel therapeutics by resorting to postbiotics that at variance from antibiotics maintain gut health in accordance with the local microbiota.

\section{AUTHOR CONTRIBUTIONS}

VO designed the figure. GR, LR, and CC wrote the paper. All authors have made a substantial, direct and intellectual contribution to the work, and approved it for publication.

\section{ACKNOWLEDGMENTS}

We thank Cristina Massi Benedetti for editing.

HLA association is to the DQ(alpha $1^{*} 0501$, beta $\left.1^{*} 0201\right)$ heterodimer. Hum Immunol. (1992) 33:133-9. doi: 10.1016/0198-8859(92)90064-T

11. Lionetti E, Catassi C. New clues in celiac disease epidemiology, pathogenesis, clinical manifestations, and treatment. Int Rev Immunol. (2011) 30:219-31. doi: 10.3109/08830185.2011.602443

12. Staab JF, Bradway SD, Fidel PL, Sundstrom P. Adhesive and mammalian transglutaminase substrate properties of Candida albicans Hwp1. Science. (1999) 283:1535-8. doi: 10.1126/science.283.5407.1535

13. Nieuwenhuizen WF, Pieters RH, Knippels LM, Jansen MC, Koppelman SJ. Is Candida albicans a trigger in the onset of coeliac disease? Lancet. (2003) 361:2152-4. doi: 10.1016/S0140-6736(03)13695-1

14. Corouge M, Loridant S, Fradin C, Salleron J, Damiens S, Moragues $\mathrm{MD}$, et al. Humoral immunity links Candida albicans infection and celiac disease. PLoS ONE. (2015) 10:e0121776. doi: 10.1371/journal.pone.01 21776

15. Harnett J, Myers SP, Rolfe M. Significantly higher faecal counts of the yeasts Candida and saccharomyces identified in people with coeliac disease. Gut Pathog. (2017) 9:26. doi: 10.1186/s13099-017-0173-1

16. Abadie V, Sollid LM, Barreiro LB, Jabri B. Integration of genetic and immunological insights into a model of celiac disease pathogenesis. Annu Rev Immunol. (2011) 29:493-525. doi: 10.1146/annurev-immunol-040210-092915

17. Bischoff SC. Physiological and pathophysiological functions of intestinal mast cells. Semin Immunopathol. (2009) 31:185-205. doi: 10.1007/s00281-009-0165-4

18. Kitamura Y, Kanakura Y, Fujita J, Nakano T. Differentiation and transdifferentiation of mast cells; a unique member of the hematopoietic cell family. Int J Cell Cloning. (1987) 5:108-21. doi: 10.1002/stem.5530050203

19. Marshall JS. Mast-cell responses to pathogens. Nat Rev Immunol. (2004) 4:787-99. doi: 10.1038/nri1460

20. Bischoff SC. Role of mast cells in allergic and non-allergic immune responses: comparison of human and murine data. Nat Rev Immunol. (2007) 7:93-104. doi: $10.1038 /$ nri2018 
21. Gurish MF, Austen KF. Developmental origin and functional specialization of mast cell subsets. Immunity. (2012) 37:25-33. doi: $10.1016 /$ j.immuni.2012.07.003

22. Dvorak AM, Monahan RA, Osage JE, Dickersin GR. Mast-cell degranulation in Crohn's disease. Lancet. (1978) 1:498. doi: 10.1016/S0140-6736(78)9 0155-1

23. Jacob C, Yang PC, Darmoul D, Amadesi S, Saito T, Cottrell GS, et al. Mast cell tryptase controls paracellular permeability of the intestine. Role of proteaseactivated receptor 2 and beta-arrestins. J Biol Chem. (2005) 280:31936-48. doi: 10.1074/jbc.M506338200

24. Konig J, Wells J, Cani PD, Garcia-Rodenas CL, MacDonald T, Mercenier A, et al. Human intestinal barrier function in health and disease. Clin Transl Gastroenterol. (2016) 7:e196. doi: 10.1038/ctg.2016.54

25. Chen CY, Lee JB, Liu B, Ohta S, Wang PY, Kartashov AV, et al. Induction of interleukin-9-producing mucosal mast cells promotes susceptibility to IgE-mediated experimental food allergy. Immunity. (2015) 43:788-802. doi: $10.1016 /$ j.immuni.2015.08.020

26. Noelle RJ, Nowak EC. Cellular sources and immune functions of interleukin9. Nat Rev Immunol. (2010) 10:683-7. doi: 10.1038/nri2848

27. Strobel S, Busuttil A, Ferguson A. Human intestinal mucosal mast cells: expanded population in untreated coeliac disease. Gut. (1983) 24:222-7. doi: 10.1136/gut.24.3.222

28. Losurdo G, Piscitelli D, Pezzuto F, Fortarezza F, Covelli C, Marra A, et al. T helper lymphocyte and mast cell immunohistochemical pattern in non-celiac gluten sensitivity. Gastroenterol Res Pract. (2017) 2017:5023680. doi: $10.1155 / 2017 / 5023680$

29. Frossi B, Tripodo C, Guarnotta C, Carroccio A, De Carli M, De Carli S, et al. Mast cells are associated with the onset and progression of celiac disease. $J$ Allergy Clin Immunol. (2017) 139:1266-74 e1. doi: 10.1016/j.jaci.2016.08.011

30. Noble SM, Gianetti BA, Witchley JN. Candida albicans cell-type switching and functional plasticity in the mammalian host. Nat Rev Microbiol. (2017) 15:96-108. doi: 10.1038/nrmicro.2016.157

31. Romani L. Immunity to fungal infections. Nat Rev Immunol. (2011) 11:27588. doi: 10.1038/nri2939

32. Underhill DM, Pearlman E. Immune interactions with pathogenic and commensal fungi: a two-way street. Immunity. (2015) 43:845-58. doi: 10.1016/j.immuni.2015.10.023

33. Staab JF, Ferrer CA, Sundstrom P. Developmental expression of a tandemly repeated, proline-and glutamine-rich amino acid motif on hyphal surfaces on Candida albicans. J Biol Chem. (1996) 271:6298-305. doi: $10.1074 / j b c .271 .11 .6298$

34. Yamaguchi N, Sugita R, Miki A, Takemura N, Kawabata J, Watanabe J, et al. Gastrointestinal Candida colonisation promotes sensitisation against food antigens by affecting the mucosal barrier in mice. Gut. (2006) 55:954-60. doi: $10.1136 /$ gut.2005.084954

35. Noverr MC, Huffnagle GB. Does the microbiota regulate immune responses outside the gut? Trends Microbiol. (2004) 12:562-8. doi: $10.1016 /$ j.tim.2004.10.008

36. Mukherjee PK, Sendid B, Hoarau G, Colombel JF, Poulain D, Ghannoum MA. Mycobiota in gastrointestinal diseases. Nat Rev Gastroenterol Hepatol. (2015) 12:77-87. doi: 10.1038/nrgastro.2014.188

37. Wheeler ML, Limon JJ, Bar AS, Leal CA, Gargus M, Tang J, et al. Immunological consequences of intestinal fungal dysbiosis. Cell Host Microbe. (2016) 19:865-73. doi: 10.1016/j.chom.2016.05.003

38. Andrews C, McLean MH, Durum SK. Cytokine tuning of intestinal epithelial function. Front Immunol. (2018) 9:1270. doi: 10.3389/fimmu.2018. 01270

39. Cataldo F, Marino V, Ventura A, Bottaro G, Corazza GR. Prevalence and clinical features of selective immunoglobulin A deficiency in coeliac disease: an Italian multicentre study. Italian Society of Paediatric Gastroenterology and Hepatology (SIGEP) and "Club del Tenue" Working Groups on Coeliac Disease. Gut. (1998) 42:362-5. doi: 10.1136/gut.42.3.362

40. Porat R, Clark BD, Wolff SM, Dinarello CA. Enhancement of growth of virulent strains of Escherichia coli by interleukin-1. Science. (1991) 254:430-2. doi: 10.1126/science. 1833820

41. Wu L, Estrada O, Zaborina O, Bains M, Shen L, Kohler JE, et al. Recognition of host immune activation by Pseudomonas aeruginosa. Science. (2005) 309:7747. doi: $10.1126 /$ science. 1112422
42. Zelante T, Iannitti RG, De Luca A, Arroyo J, Blanco N, Servillo G, et al. Sensing of mammalian IL-17A regulates fungal adaptation and virulence. Nat Commun. (2012) 3:683. doi: 10.1038/ncomms1685

43. Forbes EE, Groschwitz K, Abonia JP, Brandt EB, Cohen E, Blanchard C, et al. IL-9- and mast cell-mediated intestinal permeability predisposes to oral antigen hypersensitivity. J Exp Med. (2008) 205:897-913. doi: 10.1084/jem.20071046

44. Gerlach K, McKenzie AN, Neurath MF, Weigmann B. IL-9 regulates intestinal barrier function in experimental T cell-mediated colitis. Tissue Barriers. (2015) 3:e983777. doi: 10.4161/21688370.2014.983777

45. Renga G, Moretti S, Oikonomou V, Borghi M, Zelante T, Paolicelli G, et al. IL-9 and mast cells are key players of Candida albicans commensalism and pathogenesis in the Gut. Cell Rep. (2018) 23:1767-78. doi: 10.1016/j.celrep.2018.04.034

46. Speletas M, Vyzantiadis TA, Kalala F, Plastiras D, Kokoviadou K, Antoniadis A, et al. Pneumonia caused by Candida krusei and Candida glabrata in a patient with chronic myeloid leukemia receiving imatinib mesylate treatment. Med Mycol. (2008) 46:259-63. doi: 10.1080/13693780701558969

47. Galli SJ, Grimbaldeston M, Tsai M. Immunomodulatory mast cells: negative, as well as positive, regulators of immunity. Nat Rev Immunol. (2008) 8:478-86. doi: $10.1038 /$ nri2327

48. Lu LF, Lind EF, Gondek DC, Bennett KA, Gleeson MW, Pino-Lagos K, et al. Mast cells are essential intermediaries in regulatory T-cell tolerance. Nature. (2006) 442:997-1002. doi: 10.1038/nature05010

49. Macdonald TT, Monteleone G. Immunity, inflammation, and allergy in the gut. Science. (2005) 307:1920-5. doi: 10.1126/science.1106442

50. Hubbard TD, Murray IA, Perdew GH. Indole and tryptophan metabolism: endogenous and dietary routes to Ah receptor activation. Drug Metab Dispos. (2015) 43:1522-35. doi: 10.1124/dmd.115.064246

51. Yano JM, Yu K, Donaldson GP, Shastri GG, Ann P, Ma L, et al. Indigenous bacteria from the gut microbiota regulate host serotonin biosynthesis. Cell. (2015) 161:264-76. doi: 10.1016/j.cell.2015.02.047

52. Zelante T, Iannitti RG, Cunha C, De Luca A, Giovannini G, Pieraccini G, et al. Tryptophan catabolites from microbiota engage aryl hydrocarbon receptor and balance mucosal reactivity via interleukin-22. Immunity. (2013) 39:372-85. doi: 10.1016/j.immuni.2013.08.003

53. Agus A, Planchais J, Sokol H. Gut microbiota regulation of tryptophan metabolism in health and disease. Cell Host Microbe. (2018) 23:716-24. doi: 10.1016/j.chom.2018.05.003

54. Platten M, Nollen EAA, Rohrig UF, Fallarino F, Opitz CA. Tryptophan metabolism as a common therapeutic target in cancer, neurodegeneration and beyond. Nat Rev Drug Discov. (2019) 18:379-401. doi: 10.1038/s41573-019-0016-5

55. Belkaid Y, Harrison OJ. Homeostatic immunity and the microbiota. Immunity. (2017) 46:562-76. doi: 10.1016/j.immuni.2017.04.008

56. Cheng J, Kalliomaki M, Heilig HG, Palva A, Lahteenoja H, de Vos WM, et al. Duodenal microbiota composition and mucosal homeostasis in pediatric celiac disease. BMC Gastroenterol. (2013) 13:113. doi: 10.1186/1471-230X-13-113

57. Cervenka I, Agudelo LZ, Ruas JL. Kynurenines: tryptophan's metabolites in exercise, inflammation, and mental health. Science. (2017) 357:eaaf9794. doi: $10.1126 /$ science.aaf9794

58. Torres MI, Lopez-Casado MA, Lorite P, Rios A. Tryptophan metabolism and indoleamine 2,3-dioxygenase expression in coeliac disease. Clin Exp Immunol. (2007) 148:419-24. doi: 10.1111/j.1365-2249.2007.03365.x

59. Pallotta MT, Fallarino F, Matino D, Macchiarulo A, Orabona C. AhRmediated, non-genomic modulation of IDO1 function. Front Immunol. (2014) 5:497. doi: 10.3389/fimmu.2014.00497

60. Hmida NB, Ben Ahmed M, Moussa A, Rejeb MB, Said Y, Kourda N, et al. Impaired control of effector $\mathrm{T}$ cells by regulatory $\mathrm{T}$ cells: a clue to loss of oral tolerance and autoimmunity in celiac disease? Am J Gastroenterol. (2012) 107:604-11. doi: 10.1038/ajg.2011.397

61. Cook L, Munier CML, Seddiki N, van Bockel D, Ontiveros N, Hardy MY, et al. Circulating gluten-specific FOXP3(+)CD39(+) regulatory T cells have impaired suppressive function in patients with celiac disease. J Allergy Clin Immunol. (2017) 140:1592-603 e8. doi: 10.1016/j.jaci.2017.02.015

62. Meresse B, Malamut G, Cerf-Bensussan N. Celiac disease: an immunological jigsaw. Immunity. (2012) 36:907-19. doi: 10.1016/j.immuni.2012.06.006 
63. Sarra M, Cupi ML, Monteleone I, Franze E, Ronchetti G, Di Sabatino A, et al. IL-15 positively regulates IL-21 production in celiac disease mucosa. Mucosal Immunol. (2013) 6:244-55. doi: 10.1038/mi.2012.65

64. Zanzi D, Stefanile R, Santagata S, Iaffaldano L, Iaquinto G, Giardullo N, et al. IL-15 interferes with suppressive activity of intestinal regulatory $\mathrm{T}$ cells expanded in Celiac disease. Am J Gastroenterol. (2011) 106:1308-17. doi: 10.1038/ajg.2011.80

65. Lamas B, Natividad JM, Sokol H. Aryl hydrocarbon receptor and intestinal immunity. Mucosal Immunol. (2018) 11:1024-38. doi: 10.1038/s41385-018-0019-2

66. Dinallo V, Marafini I, Di Fusco D, Di Grazia A, Laudisi F, Dwairi R, et al. Protective effects of aryl hydrocarbon receptor signaling in celiac disease mucosa and in poly I:C-induced small intestinal atrophy mouse model. Front Immunol. (2019) 10:91. doi: 10.3389/fimmu.2019.00091

67. Roager HM, Licht TR. Microbial tryptophan catabolites in health and disease. Nat Commun. (2018) 9:3294. doi: 10.1038/s41467-018-05470-4

68. Wu H, Denna TH, Storkersen JN, Gerriets VA. Beyond a neurotransmitter: the role of serotonin in inflammation and immunity. Pharmacol Res. (2019) 140:100-14. doi: 10.1016/j.phrs.2018.06.015

69. Jackson JR, Eaton WW, Cascella NG, Fasano A, Kelly DL. Neurologic and psychiatric manifestations of celiac disease and gluten sensitivity. Psychiatr $Q$. (2012) 83:91-102. doi: 10.1007/s11126-011-9186-y

70. Choi S, Disilvio B, Fernstrom MH, Fernstrom JD. Meal ingestion, amino acids and brain neurotransmitters: effects of dietary protein source on serotonin and catecholamine synthesis rates. Physiol Behav. (2009) 98:156-62. doi: 10.1016/j.physbeh.2009.05.004

71. Pynnonen PA, Isometsa ET, Verkasalo MA, Kahkonen SA, Sipila I, Savilahti E, et al. Gluten-free diet may alleviate depressive and behavioural symptoms in adolescents with coeliac disease: a prospective follow-up case-series study. BMC Psychiatr. (2005) 5:14. doi: 10.1186/1471-244X-5-14
72. Hallert C, Sedvall G. Improvement in central monoamine metabolism in adult coeliac patients starting a gluten-free diet. Psychol Med. (1983) 13:267-71. doi: 10.1017/S003329170005087X

73. Coleman NS, Foley S, Dunlop SP, Wheatcroft J, Blackshaw E, Perkins AC, et al. Abnormalities of serotonin metabolism and their relation to symptoms in untreated celiac disease. Clin Gastroenterol Hepatol. (2006) 4:874-81. doi: 10.1016/j.cgh.2006.04.017

74. Di Sabatino A, Giuffrida P, Vanoli A, Luinetti O, Manca R, Biancheri $\mathrm{P}$, et al. Increase in neuroendocrine cells in the duodenal mucosa of patients with refractory celiac disease. Am J Gastroenterol. (2014) 109:258-69. doi: 10.1038/ajg.2013.426

75. Romani L, Zelante T, De Luca A, Fallarino F, Puccetti P. IL-17 and therapeutic kynurenines in pathogenic inflammation to fungi. J Immunol. (2008) 180:5157-62. doi: 10.4049/jimmunol.180.8.5157

76. Mayr A, Hinterberger G, Dierich MP, Lass-Florl C. Interaction of serotonin with Candida albicans selectively attenuates fungal virulence in vitro. Int J Antimicrob Agents. (2005) 26:335-7. doi: 10.1016/j.ijantimicag.2005.07.006

Conflict of Interest: The authors declare that the research was conducted in the absence of any commercial or financial relationships that could be construed as a potential conflict of interest.

Copyright (C) 2019 Renga, Bellet, Stincardini, Pariano, Oikonomou, Villella, Brancorsini, Clerici, Romani and Costantini. This is an open-access article distributed under the terms of the Creative Commons Attribution License (CC BY). The use, distribution or reproduction in other forums is permitted, provided the original author(s) and the copyright owner(s) are credited and that the original publication in this journal is cited, in accordance with accepted academic practice. No use, distribution or reproduction is permitted which does not comply with these terms. 